\title{
Dispositivos comunicacionais no mundo do trabalho: uma revisão teórica para operacionalizar o conceito
}

\section{COMMUNICATIONAL DISPOSITIFS IN THE WORLD OF THE WORK: A THEORETICAL REVIEW TO OPERATIONALIZE THE CONCEPT}

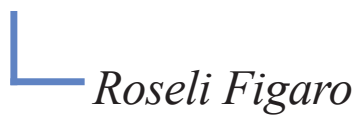

Professora associada na Escola de Comunicações e Artes e no Programa de Pós-graduação em

Ciências da Comunicação da USP. Coordenadora do Centro de Pesquisa em Comunicação e

Trabalho - CPCT/USP/CNPq.

E-mail: figaro@uol.com.br

\section{Rafael Grohmann}

Coordenador e professor do Mestrado Profissional em Jornalismo do FIAM-FAAM Centro

Universitário e professor contratado III da Escola de Comunicações e Artes da Universidade de São Paulo (USP). Coordenador do Grupo de Pesquisa Jornalismo, Mercado de Trabalho e Novas Linguagens (CNPq). Doutor em Ciências da Comunicação pela Universidade de São Paulo (USP). E-mail: rafael-ng@uol.com.br

Recebido em 24 de abril de 2017. Aprovado em 6 de junho de 2017.

\section{Resumo}

O objetivo deste artigo é discutir a produtividade do conceito de dispositivo como operador metodológico de pesquisas que têm como eixo teórico o estudo da comunicação no mundo do trabalho, sendo que a discussão se divide em três partes. Primeiro, na introdução, retoma-se o conceito de comunicação e trabalho e de comunicação no mundo do trabalho. Depois, apresentam-se algumas definições de dispositivo, identificando-se aquela com a qual se trabalha, como também são discutidas as noções de dispositivo a partir da perspectiva de diversos autores, tendo como base uma crítica a Michel Foucault e adotando a abordagem conceitual de Dominique Maingueneau. Por último, propõe-se um modo de operação do conceito de dispositivo para as pesquisas de comunicação no mundo do trabalho. Para concluir, reafirma-se a relevância do binômio comunicação e trabalho, além das contribuições que sua aplicação permite.

Palavras-chave: Comunicação e trabalho. Dispositivo. Mundo do trabalho. 


\section{Abstract}

The purpose of this article is to discuss the productivity of the dispositif's concept as a methodological operator of research whose theoretical axis is the study of communication in the world of work, considering that the discussion is divided in three parts. First, in the introduction, we discuss concepts of communication and work and of communication in the world of the work. After that, it presents some definitions of dispositif and identify the one with which it deals, as well as the notion of dispositif is discussed from several authors' perspective, based on a critique of Michel Foucault and adopting the conceptual approach of Dominique Maingueneau. At last, we propose a way of operating the concept of dispositif for communication research in the world of work. In conclusion, we reaffirm the relevance of the communication and work binomial and the contributions of its applications.

Keywords: Communication and work. Dispositif. World of the work.

\section{Introdução}

Estudar a comunicação no mundo do trabalho tem demandado ampliar o olhar do pesquisador para além do que se configurou como tradicional na literatura da área, ou seja, abordá-la como sinônimo de comunicação organizacional ${ }^{1}$. Ambas têm pontos de intersecção, mas configuram-se de modos absolutamente diferentes e buscam objetivos e metas também diferentes, sendo muitas vezes divergentes. Com relação ao trabalho, também é necessário evidenciar

que não se pode confundi-lo com emprego e não se pode reduzir as relações de trabalho à existência de um contrato salarial, ao mercado de trabalho ou às bases legalistas que regulam as obrigações e os direitos da classe trabalhadora e do patronato. De um lado, não se limita o trabalho a um instrumento de exploração dos trabalhadores pelos controladores do capital, de outro lado, porém, nossa abordagem evidencia a existência de uma acirrada luta de classes na sociedade capitalista como um dos elementos fundamentais na constituição das relações de comunicação e trabalho. (REBECHI; FIGARO, 2013, p. 3)

O mundo do trabalho é um espaço em disputa e há sempre um esforço para apagá-lo uma vez que a organização empresarial impõe o discurso da comunicação organizacional como o único reconhecido para ali circular. O mundo do trabalho é lugar das múltiplas vozes, nem sempre convergentes, lugar das subjetividades e dos conflitos.

1 Para uma discussão sobre comunicação a partir da organização e do mundo do trabalho, demarcando diferenças e especificidades de cada conceito, cf. Rebechi e Figaro (2013). 
As disputas manifestam-se nas relações de comunicação dos sujeitos que "falam" ou "representam" cada um desses espaços (FIGARO, 2008; AZEVEDO, 2015). Entender a complexidade das relações de comunicação demanda retomar o conceito de comunicação para além da ideia de mídia e, sobretudo, refutar a hipótese da linearidade comunicacional de um polo a outro. Desse modo, é necessário extirpar maniqueísmos que retiram a comunicação do âmbito social, cultural e político simultaneamente, ou seja, o conceito nessa perspectiva extirpa da comunicação a complexidade e seu aspecto conflitivo. Reafirmar a comunicação como constitutiva do ser social significa abandonar as teorias que tratam a priori a comunicação como consenso, entendimento ou qualquer outro valor relativo à aceitação, à resposta. Ao contrário, estudá-la demanda compreender as relações sociais na materialidade concreta do contexto do desenvolvimento histórico e de produção da vida em sociedade (produção e circulação dos bens necessários) para, desse modo, apreender as contradições e entendê-la - a comunicação - no processo histórico das lutas entre as classes sociais (GROHMANN, 2016).

Dar conta dessa complexidade demanda estudar a comunicação como aspecto fundante do ser social, o que quer dizer que a comunicação se institui a partir da atividade de trabalho como necessidade de realização do trabalho e do ser que trabalha. Essa compreensão remonta à ontologia do ser social como filosofia que reconhece o ser humano como totalidade objetivada nas relações sociais (LUKÁCS, 2012), ou aos moldes em que Marx e Engels salientam na Ideologia alemã (2007) ao afirmarem: "a linguagem nasce, tal como a consciência, do carecimento, da necessidade de intercâmbio com outros homens" (MARX; ENGELS, 2007, p. 34-35). Ainda podemos ressaltar a passagem de Alexis Leontiev, em $O$ desenvolvimento do psiquismo (2004, p. 92), em que se lê: "No trabalho os homens entram forçosamente em relação, em comunicação uns com os outros. Originariamente, as suas ações, o trabalho propriamente, e a sua comunicação formam um processo único". Esses autores esclarecem que a atividade de trabalho e a atividade de comunicação - binômio comunicação e trabalho - são simultâneas e formadoras de um psiquismo único que é o do ser humano.

A partir dessa perspectiva, coloca-se a necessidade de viabilizar as pesquisas na área por meio de abordagem metodológica que permita evidenciar as relações de comunicação. Nesse sentido, a proposta deste artigo é dar início à reflexão sobre a potencialidade do conceito de dispositivo, a fim de operá-lo em pesquisas que envolvam comunicação e trabalho. Com esse objetivo, discute-se neste artigo o termo de dispositivo a partir de Foucault, Agamben e outros autores que trabalharam com o conceito; depois, discute-se o dispositivo em Maingueneau. Em seguida, propõe-se um modo de operação desse conceito para as pesquisas em comunicação no mundo do trabalho. O objetivo é demonstrar 
como a noção de dispositivo, a partir de Maingueneau (2001), é produtiva para o estudo da comunicação no mundo do trabalho.

\section{Dispositivo: conceito-valise ou operacional?}

A noção de dispositivo recuperada de Michel Foucault é cambiante e múltipla. Ele explorou a ideia de "dispositivo de sexualidade" (e também "de alianças") no primeiro volume de História da sexualidade (FOUCAULT, 2014a) sem, no entanto, definir o conceito em si.

Em Vigiar e punir, Foucault (1999) também permite entrever qual é sua abordagem do conceito de dispositivo. Nela, ele discute como a sociedade transforma o regime de punição dos delitos da exposição e castigo públicos com a consequente destruição do culpado, para instituir a prisão como "aparelho de saber" que funciona para o regramento do punido, como uma prevenção. Nesse sentido, os reformatórios e prisões se constituem como dispositivos "voltados para o futuro, e organizados para bloquear a repetição do delito.” (FOUCAULT, 1999, p. 146). Em apenas um momento há uma definição (breve, por sinal) do conceito: em uma entrevista publicada em francês na revista Ornicar, dispositivo é (que em português se encontra em Foucault, 2014b):

um lugar, um conjunto decididamente heterogêneo que engloba discursos, instituições, organizações arquitetônicas, decisões regulamentares, leis, medidas administrativas, enunciados científicos, proposições filosóficas, morais, filantrópicas (FOUCAULT, 2014b, p. 364).

O dispositivo, então, é uma rede que se pode estabelecer entre esses elementos, com uma função estratégica dominante, mas Foucault

omite sistematicamente dar uma definição explícita sobre o significado que ele designa ao termo. Às vezes é utilizado como um conceito geral e outras para fazer referência a instituições, disposições arquitetônicas, discursos, procedimentos, regulamentos, artefatos ou formas de subjetividade (por exemplo, o dispositivo da sexualidade). O que fica claro é que um dispositivo não se reduz exclusivamente a práticas discursivas, senão também a práticas não discursivas e que a relação, associação, interação ou articulação entre estas resulta um requisito excludente (FANLO, 2011, p. 1-2)

Assim, entende-se o dispositivo como uma rede de relações institucionais, discursivas e normativas cuja função é disciplinar os corpos, os modos de ser e de poder existir. A noção de dispositivo, nesse sentido, é ela mesma a condição do atravessamento 
e difusão do poder político. Para Foucault (2014b), o poder não está centrado no Estado ou em uma classe dominante, mas está presente e atuante em todas as relações. Para o filósofo, não há uma imposição do poder de cima para baixo - do Estado para a sociedade - ao contrário, o poder é difuso e incorporado aos corpos, às "almas" e às instituições.

As seguintes palavras-chave compõem o campo semântico do dispositivo foucaultiano: "aparelho técnico", "recurso operador", "sistema que faz funcionar", "elementos mobilizados de um conjunto operador", "projeto normativo", "estratégia dominante". A noção de dispositivo a partir de Foucault orienta-se para uma análise da sociedade em que se obscurece a ideia de relações de poder entre classes sociais; neutraliza a abordagem de luta de classes como uma abstração da ação coletiva que faz mover a História; fragmenta e dispersa o indivíduo no ambiente social e o impele a negociar individualmente com os mecanismos operativos do dispositivo.

O também filósofo italiano Giorgio Agamben discute o dispositivo foucaultiano para dar ao conceito ainda maior amplitude. O autor afirma que, para Foucault, um dispositivo é

um conjunto heterogêneo, linguístico e não-linguístico, que inclui virtualmente qualquer coisa no mesmo título: discursos, instituições, edifícios, leis, medidas de polícia, proposições filosóficas, etc. O dispositivo em si mesmo é a rede que se estabelece entre esses elementos [...] tem sempre uma função estratégica concreta [...] resulta do cruzamento de relações de poder e de relações de saber (AGAMBEN, 2009, p. 29).

Isto é, um conceito amplo, que pode abarcar muitas coisas. Enquanto os dicionários mostram três sentidos para a palavra dispositivo (jurídico, tecnológico e militar) separando os vários significados, Foucault traria todos esses sentidos. Agamben, então, demonstra como o conceito de dispositivo é um operador importante na obra de Foucault e, ao aprofundar o estudo sobre o termo, elabora interpretação própria:

generalizando posteriormente a já bastante ampla classe dos dispositivos foucaultianos, chamarei literalmente de dispositivo qualquer coisa que tenha de algum modo a capacidade de capturar, orientar, determinar, interceptar, modelar, controlar e assegurar os gestos, as condutas, as opiniões e os discursos dos seres viventes. Não somente, portanto, as prisões, os manicômios, o Panóptico, as escolas, a confissão, as fábricas, as disciplinas, as medidas jurídicas, etc., cuja conexão com o poder é num certo sentido evidente, mas também a caneta, a escritura, a literatura, a filosofia, a agricultura, o cigarro, a navegação, os computadores, os telefones celulares - e por que não - a própria linguagem, que talvez seja o mais antigo dos dispositivos, em que há milhares e milhares de anos um primata - provavelmente sem 
se dar conta das consequências que se seguiriam - teve a inconsciência de se deixar capturar (AGAMBEN, 2009, p. 40-41).

Com isso, há uma ampliação ainda maior do conceito para abarcar não só os dispositivos de vigilância e controle foucaultianos, mas uma caneta ou um celular, ou seja, segundo a perspectiva de Agamben (2009) tudo se constitui como um dispositivo, produzindo subjetividades. Para ele, os sujeitos se posicionam entre os seres viventes (ou as substâncias) e os dispositivos que, por sua vez, são técnicas de subjetivação, de governo e de produção de subjetividades. Desse modo, aqui não há um sujeito social que, ao mesmo tempo, transforma e é transformado pelo mundo à sua volta, mas um ser "subjetivado" pelas técnicas, no qual os dispositivos produzem subjetividades.

Para Agamben (2009), os dispositivos na fase atual tornaram o processo de subjetivação e dessubjetivação sinonímias cuja expressão dá conta do atordoamento e da total captura do ser do indivíduo:

Aqui se mostra futilidade daqueles discursos bem-intencionados sobre a tecnologia, que afirmam que o problema dos dispositivos se reduz aquele de seu uso correto. Esses discursos parecem ignorar que, se todo dispositivo corresponde a um determinado processo de subjetivação (ou, neste caso, de dessubjetivação), é totalmente impossível que o sujeito do dispositivo o use "de modo correto". Aqueles que têm discursos similares são, de resto, o resultado do dispositivo midiático no qual são capturados. (AGAMBEN, 2009, p. 48).

Apesar de ensaiar que os "seres" - para usar sua própria expressão - possam agir no mundo, inclusive em relação às próprias tecnologias, furando as prescrições das normas tecnológicas, no fim, o que importa para Agamben (2009) é a captura dos seres pelos dispositivos. Para ele, a linguagem é dispositivo e a cultura também, o que o faz implodir a política para buscar restituí-la de seu papel transformador. Mas a máquina movente do dispositivo é cruel e arrebatadora, dissemina no indivíduo o germe de sua forma e de seu domínio. Nesse corpo teórico, o próprio trabalho é um dispositivo e, como uma tautologia, nos impele a reivindicar um ambiente natural e despido de cultura. Mas o "ser" fora da linguagem e, portanto, da cultura seria o quê? Um bios, um sistema biológico?

Se, por um lado, Agamben (2009) coloca o dispositivo como dependente dos sujeitos, pois não há um único modo de “usá-los", por outro, há uma concepção de sujeito que sofre processos de subjetivação/dessubjetivação e, portanto, são sujeitos "capturados" pelo dispositivo. Desse modo, é o dispositivo, e não o sujeito, o eixo central de análise. O indivíduo "dessubjetivado" é incapaz de fazer história, ou melhor, de mudar o 
jogo da história. Como se vê, o projeto teórico de Foucault e Agamben constitui perspectiva teórica em linhagem contrária àquela que procura compreender a sociedade por meio das relações concretas, históricas e materiais (o simbólico constitui o material) entre as diferentes forças e interesses de classes e dá ao sujeito o atributo de fazer história.

\section{O dispositivo na comunicação}

Para uma análise mais apurada do conceito, é importante recuperar a contribuição de outros analistas. O pesquisador brasileiro Jairo Ferreira (2006) considera que o conceito de dispositivo tem sido usado na área da comunicação de forma unidimensional, muitas vezes reduzido à ideia de tecnologia, estando muito aquém do que foi concebido por Foucault, por exemplo. Essa é uma posição recorrente nos estudos de comunicação. O dispositivo é utilizado ou como um conceito-valise ou é focalizado como aparelho tecnológico.

No dossiê da revista Hermès, de número 25, publicado em 1999 e coordenado por Geneviève Jacquinot-Delaunay e Laurence Monnoyer, há ampla discussão sobre o conceito de dispositivo. Os professores coordenadores do dossiê ressaltam a necessidade de discutir um conceito-valise como o de dispositivo, que transita desde seu significado mais tradicional próximo a meio técnico/aparelho tecnológico até as formas mais atuais dessa abordagem, relacionando o dispositivo à interface homem/máquina ou àqueles elementos que permitem a interação humana com a máquina; ou ainda às formas de controle e de ação que permeiam a relação do humano e do não humano. Na sociologia do trabalho e nas ciências ditas cognitivas, o termo também aparece nesse diapasão entre técnica e modos de uso, os mecanismos como agentes capazes de ação tais quais os dispositivos de inteligência artificial. (JACQUINOT-DELAUNAY; MONNOYER-SMITH, 1999, p. 10-11).

No artigo de Hugues Peeters e Philippe Charlier (1999), "Contribuição a uma teoria do dispositivo", há uma síntese das discussões propostas no dossiê pelos demais autores. Essa síntese parte de Foucault e discorre sobre as atualizações do termo, sobretudo, no âmbito dos usos destinados a compreender a relação humana com as tecnologias, ou seja, o jogo frequente entre o simbólico e o técnico. Essa noção se estende à inteligência artificial cujo ganho com as tecnologias de informação e comunicação se colocam como um meio ambiente capaz de feedback. Peeters e Charlier (1999) reportam-se à separação sujeito-objeto como aspecto do dispositivo, que aparece como uma racionalidade instrumental renovada diante dos avanços tecnológicos.

Nesse mesmo dossiê, Peraya (1999, p. 53) propõe o dispositivo como "uma instância, um lugar de interação e de cooperação de acordo com suas intenções, seu 
funcionamento material e simbólico, seus próprios modos de interação". Assim, coloca a tríade "sociedade-tecnologia-linguagem" como base para a compreensão do dispositivo.

Em outra obra, Peraya (2002) discute os processos de educação a distância como processo comunicacional mediado e midiatizado. Para tal, recorre ao conceito de dispositivo e, para esse seu estudo, define dispositivo como:

uma instância, um lugar social de interação e de cooperação com intenções, funcionamento e modos de interação próprios. A economia de um dispositivo - seu funcionamento - determinada pelas intenções apoia-se na organização estruturada de meios materiais, tecnológicos, simbólicos e relacionais, naturais e artificiais, que tipificam, a partir de suas características próprias, os comportamentos e as condutas sociais, cognitivas, afetivas dos sujeitos. (PERAYA, 2002, p. 4)

A discussão realizada pelo autor se dá no contexto da compreensão do que ele denomina "comunicação educativa midiatizada" para referir-se à comunicação a distância no âmbito das novas mídias, sobretudo digitais e on-line, ou no ciberespaço. Dessa forma, o esforço do autor é dar consequência operativa ao conceito e viabilizá-lo - referindo-se à definição de Anderson, de 1988 - como "qualquer coisa que organiza a realidade e fornece um instrumento de pensamento" (PERAYA, 2002, p. 5).

Conquanto sua análise busque caracterizar-se a partir do mídium, Peraya (1999) parece avançar para os aspectos socioculturais e semióticos dos dispositivos, acionando ao conceito o que ele tem de potencial metodológico. Nesse diapasão é que o autor propõe uma tipologia de análise dos dispositivos (técnico-semio-pragmático - TSP), tais como: "contextos e práticas de produção, canal, suporte de armazenamento, dispositivo técnico de restituição, modalidades de comunicação, tipo de representação e sistema semiótico, gênero de textos e tipo de discurso, contexto e práticas de recepção" (Id., 2002, p. 7). Daí se depreendem três orientações que Peraya assume: o dispositivo não é um conceito-valise, o dispositivo não é sinônimo de tecnologia, o dispositivo é um complexo técnico-semio-pragmático. Com isso, entendemos certa proximidade entre as ancoragens de Peraya e a abordagem que lhe dá Maingueneau (2001).

É, então, em Dominique Maingueneau (2001), no livro Análise de textos de comunicação, que encontramos o conceito de dispositivo comunicacional como uma proposta analítica para se compreender os processos de comunicação. Maingueneau é um linguista cuja obra trata dos processos enunciativos e da análise do discurso. Alinha-se à denominada análise do discurso francesa, em que combina criativamente a teoria linguística da enunciação à pragmática e aos aportes da genealogia de Michel Foucault. Essa mescla de 
tradições teóricas, pode-se dizer, domestica o conceito de dispositivo, tornando-o operativo. Maingueneau retira-o do âmbito mais amplo de conceito teórico-filosófico explicativo da subjetividade/dessubjetivação para torná-lo um conceito metodológico a partir do qual se pode visualizar e fazer emergir os elos pertinentes a cada situação de enunciação. Vejamos como se manifesta Maingueneau:

Quando tratamos do mídium de um gênero de discurso, não basta levar em conta seu suporte material no sentido estrito (oral, escrito, manuscrito, televisivo, etc.). É necessário também considerar o conjunto do circuito que organiza a fala. A comunicação não é, com efeito, um processo linear [...]. Na realidade, é necessário partir de um dispositivo comunicacional que integre logo de saída o mídium. O modo de transporte e de recepção do enunciado condiciona a própria constituição do texto, modela o gênero do discurso. (2001, p. 72, grifos do autor)

No excerto destacado, há algumas pistas do uso conceitual de dispositivo feito pelo autor. Primeiro, o dispositivo é comunicacional, o âmbito do discurso extrapola o texto linguístico para manifestar-se como uma totalidade de linguagens e coenunciadores dispostos na comunicação. Percebe-se a natureza operativa do conceito e a proposta de que tal operacionalidade se dê como instrumental analítico capaz de revelar os deslocamentos e os efeitos de sentidos. Essa construção é possibilitada porque Maingueneau (2001) compreende a complexidade de fatores envolvidos no processo de comunicação e desconstrói certa concepção ainda dominante de comunicação linear de um emissor para um público-alvo.

Uma categoria fundamental é a plasticidade do dispositivo comunicacional para que se compreendam os deslocamentos e efeitos de sentido. Ao alterar um de seus elementos, altera-se todo o dispositivo. A fala (oral) de um político na praça pública exige que ele use em seu discurso voz alta (se estiver sem microfone), argumentos fortes e que provoquem emoção e consigam de forma clara, simples e direta fazer o público ouvi-lo e apreciar seus argumentos; se este mesmo político fizer seu programa por meio do rádio, o mídium exigirá dele estratégias persuasivas de aproximação e individualização do discurso. Nas redes sociais, como o Facebook, este mesmo político pode dispor tanto do texto escrito quanto do audiovisual, devendo ser contundente e breve e provocando resposta imediata, viabilizada pela tecnologia. Tema, texto, mídium, tempo e espaço, coenunciadores formam um dispositivo discursivo-comunicacional que se altera quando um dos seus elementos se alterar.

Para trabalhar a noção de dispositivos comunicacionais de produção e difusão dos enunciados nos termos de Maingueneau, pode-se esquematizar a análise como segue: 
- Suportes materiais de produção: oral, impresso, manuscrito, sonoro, audiovisual.

- Situação de difusão: presencial, a distância, mediada, não mediada, interativa, não interativa

- Situação de recepção: auditório organizado, público disperso, face a face, mediada etc.

Os três elementos que compõem o dispositivo comunicacional remetem às condições de produção dos discursos, o que quer dizer que, embora o enunciador considere em seu discurso as condições para produzi-lo, mesmo contando com determinada situação de recepção e de difusão, somente o processo mesmo de acontecimento do discurso é que poderá confirmar ou não as estratégias adotadas. Ou seja, o processo comunicacional só se efetiva quando coloca em relação os coenunciadores (ou os sujeitos) do discurso. Há entre os dispositivos adotados como estratégia o inédito da atividade comunicacional. O dispositivo não é um circuito fechado, nem mesmo um sistema autopoético que se autoalimenta.

Em um artigo de 2002, na revista Vox-Poetica, Maingueneau analisa o percurso do texto e do discurso para a linguística e para a literatura, numa crítica aos cânones que cerram a análise ao corpo do texto, abstraindo contexto, condições de produção, história e autor/autoria. Maingueneau busca no dispositivo a forma da explicação de seu ponto de vista, sendo sua expressão bastante similar ao que já havia enunciado em Análise de textos de comunicação (2001). Assim, o excerto que segue corrobora com a discussão que se faz aqui apontando o dispositivo comunicacional como uma pista metodológica e epistêmica para a análise da comunicação:

Hoje, sem dúvida, se tem renunciado a definir um centro, ou, ao menos, se há um centro é em um sentido bem diferente, visto que é o dispositivo de comunicação ele mesmo este centro. Ao se apreender as obras como discurso, ao se fazer da enunciação o eixo de inteligibilidade do discurso literário, se desloca seu eixo: do texto para um dispositivo de fala ou das condições do dizer atravessando o dito e onde o dito reenvia às suas próprias condições de enunciação (o status do escritor associado ao seu modo de posicionamento no campo literário, os papéis destinados aos gêneros, a relação destinatário construído pela obra, os suportes materiais e os modos de circulação dos enunciados...). Esse dispositivo é alguma coisa de uma vez textual e sócio-histórico. (MAINGUENEAU, 2002, tradução nossa) ${ }^{2}$

2 No original: “Aujourd'hui on a sans doute renoncé à définir un centre, ou, du moins, s'il y a un centre c'est en un sens bien différent, puisque c'est le dispositif de communication lui-même. En appréhendant ainsi les oeuvres comme discours, en faisant de l'énonciation l'axe d'intelligibilité du discours littéraire, on déplace son axe : du texte vers un dispositif de parole où les conditions du dire traversent le dit et où le dit renvoie à ses propres conditions d'énonciation (le statut de l'écrivain associé à son mode de 
Depreende-se das reflexões de Maingueneau $(2001,2002)$ sobre os dispositivos que esse conceito, ao ser aplicado como estratégia metodológica de construção do objeto, dialoga com a compreensão da analítica que aqui se propõe de relações de comunicação no mundo do trabalho. O conceito de dispositivo das relações de comunicação no mundo do trabalho torna operativa a observação in loco, dando ao pesquisador/observador pistas sobre o que e como observar nas relações de comunicação.

\section{Aplicações possíveis}

Os dispositivos comunicacionais no mundo do trabalho comportam uma complexa rede de: coenunciadores, gêneros de discurso, objetos e instrumentos sociotécnicos, arquitetura específica, regras de como agir, normas profissionais, procedimentos técnicos e hierarquias. Tentemos identificar os suportes materiais de produção dos discursos: o oral, por exemplo, comporta as reuniões; as ordens transmitidas coletiva e individualmente pela hierarquia da empresa; as conversas entre profissionais sobre os temas do trabalho; todas as trocas orais sobre o trabalho; todas as trocas orais informais não necessariamente sobre o trabalho.

Nessa perspectiva, a situação de difusão é definida em espaços específicos onde cada uma dessas trocas orais de gêneros discursivos podem ocorrer. As trocas sobre o trabalho na forma de ordens e/ou orientações podem se dar de maneira presencial, em situação de recepção que torna mais ou menos tensa a interação, como também podem ser nas salas das chefias, no local de trabalho do empregado ou em salas de reuniões específicas para essas trocas. Elas também acontecem não presencialmente, por meio de mediação técnica, o que coloca certo distanciamento e menor tensão na situação de recepção. Essas trocas orais oficiais são geralmente acompanhadas por documentos ou normas técnicas escritas, as quais registram na forma de uma escrita técnica, padrão, como se deve proceder. Em todas essas ocasiões, há uma postura gestual adequada, um tratamento relacional que considera a hierarquia, um conjunto lexical técnico e de tratamento adequado ao protocolo da empresa.

Para além da comunicação cujo fluxo é iniciativa da empresa por meio de suas diretrizes e orientações, há a comunicação para o exercício do trabalho, que se dá entre os pares na realização da tarefa. Elas são tradicionalmente feitas de forma oral e presencial, no local em que se situa o trabalhador. Esse cenário é rico e todos os elementos do

positionnement dans le champ littéraire, les rôles attachés aux genres, la relation au destinataire construite à travers l'oeuvre, les supports matériels et les modes de circulation des énoncés...). Ce dispositif est quelque chose d'à la fois textuel et sociohistorique". 
dispositivo comunicacional concorrem para a produção de sentidos. Uma piada durante o trabalho tem a função de reforçar laços, de tornar a situação menos tensa e amenizar o cansaço. Um sinal com a mão pode indicar uma diretiva de ação; todo o corpo comunica e compõe o suporte material de produção da enunciação.

Além da oralidade, há suportes diversos criados pelos trabalhadores para o exercício de sua tarefa e que muitas vezes são "traduções" não autorizadas das normas oficiais: pequenos bilhetes, pedaços de madeira, lousas com dizeres e medidas, paredes e máquinas marcadas com sinais, letras, números são elementos discursivos que dão apoio ao trabalho. Pequenos bilhetes transmitidos de um coletivo para outro, conversas de corredor fazendo acertos sobre o como fazer. As situações privilegiadas para essas trocas são as presenciais, mas hoje existem mecanismos para as situações de difusão a distância. Aplicativos, como o WhatsApp, podem permitir todo o desenvolvimento de trocas formais e informais sobre e como trabalhar.

Identificar os suportes materiais de produção, as situações de difusão e as de recepção permitem ter dimensão da complexidade do dispositivo comunicacional no mundo do trabalho, bem como de sua plasticidade e dos inúmeros possíveis intervenientes que criam condições específicas de comunicação. Em uma situação de trabalho em que a situação de recepção se dá em local com muito barulho, as trocas linguísticas são acompanhadas por gestual intenso e os corpos têm maior aproximação.

No teletrabalho, a situação de difusão e de recepção é dúbia e dupla, ao mesmo tempo que se comunica com um interlocutor a distância e com outro presencial, próximo. Muitas vezes, sinais e linguagem gestual-corporal comentam em contraposição ao que se faz a distância. Uma teleoperadora, por exemplo, atende ao cliente e busca tratar do produto para esse consumidor a partir do script que a empresa estabelece para o contato e, simultaneamente, estabelece um gestual que comenta aos parceiros no local de trabalho (presencial) o que se passa no contato com o cliente. São diferentes dispositivos que operam simultaneamente: a fala, via telefone, o script que deve ser seguido para o contato com o cliente, o interlocutor cliente como coenunciador, a situação a distância, a relação comercial/profissional. Ao mesmo tempo, o trabalhador em situação presencial sendo controlado pela hierarquia e relacionando-se com os colegas de trabalho, por meio de estratégias que vão dos sinais com as mãos ao cochicho e ao gestual do corpo, em uma situação de difusão muito controlada e reprimida.

Para o pesquisador das relações de comunicação no mundo do trabalho, o conceito de dispositivo permite a elaboração de protocolos de observação capazes de apreender os elementos de situações e suportes de produção do discurso, situação de difusão e de recepção desse discurso. 
Para concluir, a proposta de dispositivo comunicacional de Maingueneau tem um valor metodológico e operativo, porque permite a análise objetiva do processo comunicacional no mundo do trabalho. Portanto, propõe-se aqui uma reflexão sobre como fazer para o conceito de dispositivo: a) sair das amarras de conceito-valise para considerar as relações entre os sujeitos sociais a partir da vida material e suas contradições; b) recolocar a problemática do sujeito social em outro patamar; c) considerar o dispositivo comunicacional a partir dos processos comunicacionais e não o restringir à mídia e/ou aos meios tecnológicos.

Maingueneau (2001) nos ajuda, então, a compreender o dispositivo considerando condições de produção, discurso e recepção, sendo na circulação que o dispositivo ganha sentido. A vantagem que essa abordagem nos oferece é a de avançar em relação à operacionalidade do conceito, tratando-o como elemento compositivo das situações comunicacionais. $\mathrm{O}$ dispositivo deixa de ser um conceito-valise em que os conflitos e embates entre as classes são generalizados a tal ponto que podem ser dissimulados. A sua importância é de nos proporcionar a operacionalização do conceito que, na formulação de um protocolo metodológico de pesquisa, permita uma abordagem do comunicacional sem extirpá-lo da centralidade dos sujeitos sociais e das lutas de classes nas relações de comunicação.

\section{Referências}

AGAMBEN, G. O que é um dispositivo? In: O que é o contemporâneo? e outros ensaios. Chapecó: Argos, 2009.

AZEVEDO, J. A. Centralidade da atividade de comunicação e de trabalho: um estudo da comunicação em fábricas recuperadas por experiências autogestionárias. 2015. 280 f. Tese (Doutorado em Comunicação) - Escola de Comunicação e Artes, Universidade de São Paulo, São Paulo, 2015. Disponível em: <https://goo.gl/f77MNp>. Acesso em: 24 out. 2017.

FERREIRA, J. Uma abordagem triádica dos dispositivos midiáticos. Líbero, São Paulo, ano IX, n. 17, p. 138-145, jun. 2006.

FIGARO, R. Relações de comunicação no mundo do trabalho. São Paulo: Annablume, 2008.

FOUCAULT, M. Vigiar e Punir. Petrópolis: Vozes, 1999. . História da sexualidade: a vontade de saber. São Paulo: Paz e Terra, 2014a. v. 1. Microfisica do poder. São Paulo: Paz e Terra, 2014b.

GROHMANN, R. N. As classes sociais na comunicação: sentidos teóricos do conceito. 2016. 365 f. Tese (Doutorado em Ciências da Comunicação) - Escola de Comunicações e Artes, Universidade de São Paulo. São Paulo, 2016. Disponível em: <https://goo.gl/9Y3fpK>. Acesso em: 24 out. 2017. 
JACQUINOT-DELAUNAY, G.; MONNOYER-SMITH, L. (Coords.). Le dispositif entre usage et concept. Paris: CNRS, 1999. (Coleção Hermès). Disponível em: <https://goo.gl/m1t2R>. Acesso em: 23 abr. 2016 .

LEONTIEV, A. O desenvolvimento do psiquismo. São Paulo: Centauro, 2004.

LUKÁCS, G. Para uma ontologia do ser social. São Paulo: Boitempo, 2012. v. 1.

MAINGUENEAU, D. Análise de textos de comunicação. São Paulo: Cortez, 2001.

. Linguistique et littérature: le tournant discursif. Vox-Poetica. Lettre et Sciences Humaines, 2002. Disponível em: <https://goo.gl/eS1uSw>. Acesso em: 20 jan. 2017.

MARX, K.; ENGELS, F. A ideologia alemã. São Paulo: Boitempo, 2007.

PEETERS, H. ; CHARLIER, P. Contributions à une théorie du dispositif. Hermès, Paris, n. 25, p.15-23, 1999.

PERAYA, D. Médiation et médiatisation: le campus virtuel. Hermès, Paris, n. 25, p. 153-167, 1999. O ciberespaço: um dispositivo de comunicação e de formação midiatizada. In: ALAVA, S. (Org.) Ciberespaço e formações abertas: rumo a novas práticas educacionais? Porto Alegre: Artmed, 2002. p. 25-52.

REBECHI, C.; FIGARO, R. A comunicação no mundo do trabalho e a comunicação da organização: duas dimensões distintas. Animus: Revista Interamericana de Comunicação Midiática, Santa Maria, v. 12, n. 24, p. 1-23, 2013. 